\title{
Prevalence of intestinal parasites in faecal droppings of swine in Pankshin urban, Pankshin local government area, Plateau state, Nigeria
}

\author{
Agumah Nnabuife Bernard ${ }^{1}$, Daminabo V. ${ }^{2}$, Ekam E. ${ }^{3}$, Okonkwo E. C. ${ }^{1}$, Nwuzo A. C. ${ }^{1}$, \\ Afiukwa F. N. ${ }^{1}$, Agah M. V. ${ }^{1}$ \\ ${ }^{1}$ Department of Applied Microbiology, Ebonyi state University, Abakaliki, Nigeria \\ ${ }^{2}$ Department of Microbiology Rivers State College of Arts and Sciences, Rivers State, Nigeria \\ ${ }^{3}$ Federal School of Medical Laboratory Sciences, Jos University Teaching Hospital, Plateau State, Nigeria
}

Email address:

buifewenemighty@gmail.com (A. N. Bernard)

\section{To cite this article:}

Agumah Nnabuife Bernard, Daminabo V., Ekam E., Okonkwo E. C., Nwuzo A. C., Afiukwa F. N., Agah M. V.. Prevalence of Intestinal Parasites in Faecal droppings of Swine in Pankshin Urban, Pankshin Local Government Area, Plateau State, Nigeria. American Journal of Life Sciences. Vol. 3, No. 2, 2015, pp. 119-122. doi: 10.11648/j.ajls.20150302.19

\begin{abstract}
A total of 240 faecal samples of swine from Pankshin urban was collected and examined for the incidence of intestinal parasites. A total prevalence rate of 32.5\% was recorded. With respect to location, Special site recorded the highest prevalence (10\%) while Yimtul recorded the lowest prevalence (6.67\%). Based on incidence of individual species Ascaris suum recorded the highest prevalence while Strongyloides recorded the lowest prevalence (1.9\%). The outdoor method of pig breeding in most areas of Pankshin was assumed to be a major factor in the distribution of these parasites since pigs are raised for both commercial and subsistent purpose.
\end{abstract}

Keywords: Swine, Parasites, Fecal

\section{Introduction}

Gastrointestinal parasites are responsible for substantial loss of productivity in swine and other livestock industry. They constitute a major impediment to efficient and profitable livestock production (Boes et al., 2000; Joachim et al., 2001). Gastrointestinal parasitism in swine affects swine's performance in terms of efficient feed conversion, poor growth rate, reduced weight gain and the condemnation of affected organs after slaughter (Nsoso et al., 2000). In Nigeria, livestock production sector is vital not only because of its economical benefits but because over $80 \%$ of the population are involved in one way or the other in Agriculture (Otuma and Udenwa, 2009).

Swine Internal parasites, estimated to cost 250million dollars annually in the United States are not considered to be swine killers. Internal parasites devitalize pigs by robbing them of essential nutrients and injuring vital organs (Myer and Walker, 1999). Pigs heavily parasitized are more susceptible to disease, the resulting diseases being major causes of zoonosis and economic loss. Primarily, raising pigs in pens enhances a better hygienic profile unlike when swine are raised outside pens, thus exposure of pigs outside suitable pens disposes them to the danger of parasitic infections. Hence man can be directly or indirectly affected.

The application of raw livestock wastes in agricultural soils is one of the most extended practices for residue management (Bornay et al, 2009). However, there are diverse components in their composition especially pathogens, heavy metals and salts, which are potentially dangerous for the environment and for man. Swine faeces are a source of pathogenic organisms, mainly bacteria, viruses, parasites and fungi. The most frequently found parasites in intensified hog farming are Ascaris sum, Trichuris suis, strongyla, Balantidium coli and Cryptosporidium spp (CaballeroHernendezet al, 2004). Some of these have been able to survive in the environment.

Parasites of pigs and their potential to infect humans have recently become a major issues among the public because of recent outbreaks of water-borne parasitic disease (Olson and Guselle, 2000).

Water-borne transmission of Intestinal parasites has been linked to domestic livestock and farming practices. The danger for humans becoming infected with protozoa of 
animal origin is higher than with helminthes (Burton and Burner, 2003). Cryptosporidum species a robust oocyst for example, can survive for long period outside the host, particularly in moist environment. Mawdsley et al (1996), demonstrated that Cryptosporidium oocysts can move through various soil type and Lindergard et al (2001) concluded that in general, oocysts isolated from soil samples are regarded as being viable and potentially infective to humans. Ascaris suum, eggs were not destroyed when the solid fraction of swine manure was ensiled for 56 days (Caballero Hernandez et al, 2004), therefore could be dangerous in the feeding of other animals.

Control of parasitic infection of swine is aimed at reducing their detrimental effects. Management should be aimed at breaking the life cycle of these parasites as well as to prevent other diseases of swine.

\section{Materials and Methods}

\subsection{Study Area}

Pankshin urban is the capital (headquarters) Pankshin Local Government Area located in Plateau Central Senatorial zone, Plateau State, Nigeria. The people are predominantly of the Ngas tribe. The area is surrounded by hills and the cold season predominates. In Pankshin, Pigs are raised for both commercial (economic) and subsistent purposes.

\subsection{Sample Collection}

240 feacal samples passed out by pigs were collected from four major areas of the town. They were collected randomly from the following areas, Special site (SS), Lowcost housing estate (LC), New layout/Monday market (N) and Yimtu/GRA(YG). In each collection 10 samples each were collected. Collection was on 6 different occasions

\subsection{Laboratory Examination}

The faecal samples were macroscopically examined for the presence of blood and adult parasite with naked eyes.

Microscopic Examination was also carried out using direct normal saline method and Iodine method.

\subsubsection{Normal Saline Method}

A drop of $(0.85 \%)$ normal saline was placed at the centre of a clean grease free slide and a small portion of the stool was picked with the help of an applicator stick and smear was made in the drop.

It was covered with a cover slip and examined under the microscope using $x 10$ and $x 40$ objectives respectively.

\subsubsection{Iodine Method}

A drop of $1 \%$ iodine was placed at thecentre of a clean grease free glass slide and a small portion of stool specimen was emulsified in the drop using applicator sticks.

The smear was covered with a cover slip and examined under the microscope using x10 and x40 objective respectively.

\section{Formal Ether Sedimentation Technique}

The formal ether sedimentation technique was employed to analyze the collected samples for intestinal parasites.

About $1 \mathrm{~g}$ of feaces is placed in $10 \mathrm{ml}$ of $10 \%$ formol solution in a screw capped bottle and shaken vigorously to mix then filtered with a wire sieve into a centrifuge tube. 3$5 \mathrm{ml}$ of diethyl ether was added to the supernatant, the tube stoppered and mixed vigorously for 1minute. It was centrifuged at approximately 200rpm for five minutes.

A stick was used to loosen the layer of faecal debris from the side of the tube. The tube was inverted to discard the ether, fecal debris and formol solution. The bottom of the tube was tapped to suspend the sediment and a drop of the sediment was placed on a clean grease free glass slide and covered with cover slip. It was examined microscopically using $\times 10$ and $\times 40$ objectives.

\section{Results}

Generally, a total prevalence of $32.5 \%$ was recorded for intestinal parasites from the 240 samples analyzed. A total of 78 samples were positive. Special site had the highest prevalence $(10 \%)$ while Yimtul had the lowest prevalence (6.67\%). Based on species, Ascaris suum had the highest prevalence, (18.5\%) followed by Balantidium coli $(13.0 \%)$ and Schistosoma japonicum, (13.0\%). Strongyloides had the lowest prevalence.

Table 1. Prevalence of intestinal parasites in faecal droppings of swine in Pankshin Urban.

\begin{tabular}{lll}
\hline Parasite & Number examined & Prevalence (\%) \\
\hline Positive & 78 & $32.5 \%$ \\
Negative & 162 & $67.5 \%$ \\
Total & 240 & $100.0 \%$ \\
\hline
\end{tabular}

Table 2. Prevalence in relation to location

\begin{tabular}{lllll}
\hline Location & No examined & Positive & Negative & Prevalence (\%) \\
\hline Special site & 60 & 24 & $(36)$ & $10 \%$ \\
New layout & 60 & 19 & $(41)$ & $7.92 \%$ \\
Low-cost & 60 & 19 & $(41)$ & $7.92 \%$ \\
Yimtul / GRA & 60 & 16 & $(44)$ & $6.67 \%$ \\
Total & 240 & 78 & $(162)$ & $32.5 \%$ \\
\hline
\end{tabular}

Table 3. prevalence in relation to parasite species

\begin{tabular}{lll}
\hline & Positive & Prevalence (\%) \\
\hline (Protozoa) Balantidium coli & 10 & $13.0 \%$ \\
Entamoebahistolytica & 9 & $11.1 \%$ \\
Giardia duodenalis(Helminths); & 19 & $5.6 \%$ \\
Ascarissuum & 14 & $18.5 \%$ \\
Enterobiusvermicularis & 7 & $9.3 \%$ \\
Tricuris suis & 7 & $9.3 \%$ \\
Strongyloides & 2 & $1.9 \%$ \\
Fasciola hepatica & 7 & $9.3 \%$ \\
Schistosomajaponicum & 10 & $13.0 \%$ \\
Schistosomamansoni & 2 & $1.9 \%$ \\
Teaniasolium & 9 & $11.1 \%$ \\
\hline
\end{tabular}




\section{Discussions}

The safety of food we obtain from animals for human consumption has become a public health concern. Indiscriminate accumulation of animal fecal waste on land is considered a potential source of environmental contamination and therefore a public health risk. Parasites of pigs and their potential to infect humans could become a major issue among the public if not kept in check.

From this research, a total prevalence of $32.5 \%$ was recorded. This could be assumed to be lower than average considering the number of samples analyzed. Specifically $70.5 \%$ of the positive samples were recorded for helminths while $29.5 \%$ was recorded for protozoa. Considering the risk this posse to humans, this result relatively goes in contrast with the assertion by Burton and Turner (2003) that the danger for humans becoming infected with protozoa with animal origin is higher than with helminthes.

With respect to species prevalence, Ascaris suum had the highest prevalence (18.5\%) followed by Balantidium coli and Schistosoma japonicum with prevalence of each (13.0\%). Entamoeba histolytica and Taenia solium both recorded a prevalence of $11.1 \%$ each. Schistosoma mansoni and Strongyloides recorded the lowest prevalence (1.9\% each).

This is in agreement with findings of past studies where $A$. suum was reported as the most prevalent parasite in scavenging pigs (Kumar et al., 2002; Ngowi et al., 2004; Tamboura et al., 2006) and also in semi-intensively managed pigs (Nsoso et al., 2000).

This study is also in line with the work of Bornay et al, (2009), in which several protozoa (Balantidium coli, Entamoeba coli) and helminthes (Ascaris suum, Trichuris suis, Fasciola hepatica, and strongylida) were identified. Bornay et al reported Balantidium coli in $78 \%$ of pig slurries and this could be likened to the relatively high prevalence of Balantidium coli from positive samples in this work. This high prevalence could be attributed to the role of pig as a principal reservoir of this protozoa. Weng et al, (2004) also recorded Balantidium coli positive from 1716 of 3636 samples analyzed. Thus giving him the highest prevalence from that analysis.(42.7\%).

In contrast with this work Ascaris recorded very low prevalence with the works of Bornay et al, (2009) and Weng et al, (2004). A prevalence of $17 \%$ and $2.5 \%$ were recorded respectively. Strongyloides which recorded the lowest prevalence with this work recorded the highest prevalence (56\%) in pig slurries analyzed by Bornay et al, (2009).

The general habit of pigs disposes them to infestation by a lot of parasites, some of which are somewhat accidental.

Distribution of prevalence with respect to location showed that the densely populated areas; special site, New layout and Low-cost areas gave the highest prevalence. This could pose some risks as most individuals who rear swine in these areas take to outdoor methods which predisposes both the pigs and man to parasites. Yimtul which has the lowest population density presented a low prevalence. Hence it could be assumed from these areas that the higher the population density (especially pig farmers) the higher the prevalence of parasites. Previous study has shown that there is the possibility of pigs acting as transport host for human parasites (Steenhard et al., 2000). The presence of hookworm in the pigs poses health risk for humans.

In conclusion, the result from this study has revealed that pig faeces could be an important source for some parasites capable of infecting humans. In a community setting where pigs are reared and pig meat is consumed by a large part of the population, they could be involved in zoonotic helminthosis and a further investigation should study the possible impact of parasitic infections of pigs in Nigeria.

\section{References}

[1] Anderson, T.J., Jaenike J. (1997). Host specificity, evolutionary relationships and macro geographic differentiation among Ascaris populations from humans and pigs.Parasitology 115:325-342.

[2] Atwill E.R., Sweitzer R.A., Pereira M.G., Gardner I.A., Van vuren D., and Boyce W.M. (1997).Prevalence and risk factors for shedding Crytosporidiumoocysts and Giardia cysts within feral pigs. Applied and environmental microbiology 63:39463949.

[3] Boes J, Willingham III A. L., Shi F. H., Hu X.G., Eriksen L., Nansen P., Stewart T. B. (2000). Prevalence and distribution of pig helminths in the Dongting Lake Region (Human Province) of the People's Republic of China. J. Helminthol. 74:45-52.

[4] Bornay F. J., Navarro L., Garcia-Orenes F., Araex H., PerezMurcia M.D., and Moral R., (2009).Department of Agrochemistry and environment. University Miguel Hernandez de Elche, Spain. f.bornay@ umh.es

[5] Burton C.H., Turner, C. (2003). Health risks from pathogens in livestock manure. In manure management treatment strategies for sustainable agriculture. ED. Silcos Research Institute, UK. 451pp.

[6] Imperato S., Foresi C., Martinetto P., (1968). Comparative analysis of antigen constitution of Ascaris lumbricoids var hominis and varsuum. Revista dell' instituto sieroterapico Italiano.43; 253-60.

[7] Joachim A., Dulmer N., Dangschies A., Roepstorff A (2001). Occurrence of helminths in pig fattening units with different management systems in Northern Germany. Vet. Parasitol. 96:135-146.

[8] Kumar S., Prasad K. D., Singh S. K., Kumar S (2002). Prevalence of common gastrointestinal parasites in pigs at and around Ranchi, Jharhand. Ind. J. Anim. Sci. 72:35-37.

[9] Kurimoto H. (1974). Morphological, biochemical and immunological studies on the differences between Ascaris lumbricoids; Linnaeus 1758 and Ascaris suum;Goaze 1782.Japanese Journal of parasitology 23:251-67.

[10] Lindergard G., Wade S. E, Schaaf S., Barwick R. S., Mohammed H. O. (2001) Detection of Cryptosporidium oocysts in soil samples by enzyme-linked immunoassay. Vet parasitol. 94:163-176. 
[11] Mawdsley J., Brooks A., Merry R. (1996) Movement of protozoan pathogen Cryptosporidium parvum through three contrasting soil types. Biol. Fert. Soils, 21:30-36.

[12] Myer R.O., Walker W. R. (1999) Controlling Internal parasites of Swine. Cooperative Extension service.Institute of food and Agricultural services. Florida

[13] Ngowi H. A., Kassuku A. A., Maeda G. E, Boa M. E, Willingham A. L (2004). A slaughter slab survey for extraintestinal porcine helminth infections in Northern Tanzania. Trop. Anim. Health Prod. 36:335-340.

[14] Nsoso S. J., Mosala K. P., Ndebele R. T., Ramabu S. S (2000). The prevalence of internal and external parasites in pigs of different ages and sexes in southeast district, Botswana. Onderstepoort J. Vet. Res. 67:217-220.

[15] Olson M. E., Thorlakson C. L., Deselliers L., Morck D. W., McAllister T.A. (1997) Giardia and cryptosporidium in Canadian farm animals. Veterinary parasitology 68:375-381

[16] Otuma M. O., Uchewa E. N. (2009). Evaluation of the Production Characteristics of West African Dwarf and West African $\times$ Red Sokoto Goats of Nigeria. Proceedings of the 42nd Annual Conference of Agricultural Society of Nigeria (ASN) held at Ebonyi State University Abakaliki, Nigeria. pp. 622-625.
[17] Smith J. D. (1996) Animal parasitology. Cambridge university press

[18] Steenhard N. R., Storey P. A., Yelifari L., Pit D. S., Nansen P., Polderman A. M. (2000). The role of pigs as transport hosts of the human helminths Oesophagostomum bifurcum and Necator americanus. Acta Trop. 76(2):125-130.

[19] Tamboura H. H., Banga-Mboko H., Maes D., Youssao I, Traore A, Bayala B, Dembele MA (2006). Prevalence of common gastrointestinal nematode parasites in scavenging pigs of different ages and sexes in Eastern Centre Province, Burkina Faso. Onderskpoort J. Vet. Res. 73:53-60.

[20] United States department of Agriculture. Report (2006)

[21] Wagner B., Polly L (1997) Acarissuumprevalence and intensity: an abattoir survey of Market hogs in Saskatchewan. Veterinary parasitology 73:309-313.

[22] Weng Y.B., Hu Y.J., Li Y., Li B.S., Lin R.Q., xie D. H., Gasser R. B., Zhu X.Q. (2004) Survey of intestinal parasites in pigs from intensive farms in Guangdong province, Peoples republic of China.Veterinary parasitology. wikipedia. 2009. 